\title{
Perinatal Gene-Gene and Gene-Environment Interactions on IgE Production and Asthma Development
}

\author{
Jen-Chieh Chang, ${ }^{1,2}$ Lin Wang, ${ }^{3}$ Rong-Fu Chen, ${ }^{4}$ and Chieh-An Liu ${ }^{3}$ \\ ${ }^{1}$ Institute of Biomedical Sciences, National Sun Yat-Sen University, Kaohsiung 804, Taiwan \\ ${ }^{2}$ Genomic and Proteomic Core Laboratory, Department of Medical Research, Kaohsiung Chang Gung Memorial Hospital and Chang \\ Gung University College of Medicine, Kaohsiung 833, Taiwan \\ ${ }^{3}$ Department of Pediatrics, Kaohsiung Chang Gung Memorial Hospital and Chang Gung University College of Medicine, \\ Kaohsiung 833, Taiwan \\ ${ }^{4}$ Department of Medical Research, Chang Bing Show Chwan Memorial Hospital, Changhua 505, Taiwan
}

Correspondence should be addressed to Chieh-An Liu, liuca@adm.cgmh.org.tw

Received 31 July 2011; Revised 1 November 2011; Accepted 17 November 2011

Academic Editor: Kuender D. Yang

Copyright ( 2012 Jen-Chieh Chang et al. This is an open access article distributed under the Creative Commons Attribution License, which permits unrestricted use, distribution, and reproduction in any medium, provided the original work is properly cited.

\begin{abstract}
Atopic asthma is a complex disease associated with IgE-mediated immune reactions. Numerous genome-wide studies identified more than 100 genes in 22 chromosomes associated with atopic asthma, and different genetic backgrounds in different environments could modulate susceptibility to atopic asthma. Current knowledge emphasizes the effect of tobacco smoke on the development of childhood asthma. This suggests that asthma, although heritable, is significantly affected by gene-gene and gene-environment interactions. Evidence has recently shown that molecular mechanism of a complex disease may be limited to not only DNA sequence differences, but also gene-environmental interactions for epigenetic difference. This paper reviews and summarizes how gene-gene and gene-environment interactions affect IgE production and the development of atopic asthma in prenatal and childhood stages. Based on the mechanisms responsible for perinatal gene-environment interactions on IgE production and development of asthma, we formulate several potential strategies to prevent the development of asthma in the perinatal stage.
\end{abstract}

\section{Introduction}

Atopic asthma is a complex disease associated with IgEmediated allergic reactions. Most allergens elicit IgE antibodies, which bind to mast cells; when cross-linked, the mast cell releases inflammatory mediators that cause bronchospasm and mucus formation [1]. Nonatopic asthma refers to inflammation and constriction of the airways that are not caused by exposure to an allergen. As with numerous illdefined diseases in which numerous extrinsic influences and genetic factors contribute to onset of the disease, the term "complex disease" is applied. Such terminology refers to asthma as caused by a complex relationship between genetic and environmental components, resulting in the clinical manifestations of atopic asthma. Systemic administration of humanized anti-IgE antibodies causes a 95-99\% decrease in serum IgE, along with anti-inflammatory feature of asthma [2], which supports the IgE-mediated mechanism of atopic asthma. Numerous genome-wide association (GWA) studies have identified more than 100 genes in 22 chromosomes associated with atopic asthma $[3,4]$. Moreover, genetic backgrounds and environmental exposures could modulate susceptibility to asthma $[5,6]$. This suggests that asthma, although heritable, is significantly affected by environmental factors. Evidence has recently shown that molecular mechanisms of atopic disease may not be limited to DNA sequence differences, but also gene-environmental interactions for epigenetic difference and/or regulatory T cells (Treg) $[7,8]$. We describe recent advances in our understanding based on the mechanisms responsible for gene-gene and geneenvironment interactions on IgE production and development of atopic asthma in the perinatal stage. 
TABLE 1: Gene-gene interactions on IgE production and asthma phenotype.

\begin{tabular}{|c|c|c|}
\hline \multicolumn{3}{|c|}{ Total IgE levels/ asthma phenotype Gene-gene interactions } \\
\hline \multirow{6}{*}{ Prenatal } & \multirow{6}{*}{$\begin{array}{l}\text { IgE levels } \\
\text { (cord blood, } \\
\text { infant blood) }\end{array}$} & CD86-VTCN1 [9] \\
\hline & & IL13-CCL17 [10] \\
\hline & & $I L 1 R L 1-B P I[11]$ \\
\hline & & TGFBR2-IL2RA [12] \\
\hline & & IL13-CCL17-CXCL10 [10] \\
\hline & & MD2-ITGB2-BPI [11] \\
\hline \multirow{26}{*}{ Childhood } & \multirow{8}{*}{ IgE levels } & $C D 14-A O A H[13]$ \\
\hline & & IL1RL1-NOD1 [11] \\
\hline & & IL13-IL4RA $[14,15]$ \\
\hline & & IL13-IL13RA1 [16] \\
\hline & & IL13-TARC [17] \\
\hline & & TLR2-TGFBR2 [12] \\
\hline & & MD2-MAP3KIP2-BPI [11] \\
\hline & & TLR2-IL6RA-IL2RA [12] \\
\hline & \multirow{18}{*}{ Asthma } & $C D 14-A O A H[13]$ \\
\hline & & CD274-LILRA4 [9] \\
\hline & & GSNOR-B2AR [18] \\
\hline & & IL4-IL4RA [19] \\
\hline & & IL6-IL6R [20] \\
\hline & & IL13-IL4R [21] \\
\hline & & IL13-IL4RA $[15,17,22]$ \\
\hline & & LTA4H-ALOX5AP [23] \\
\hline & & SOCS1-MAP3K7IP1 [11] \\
\hline & & TNC-NPSR1 [24] \\
\hline & & $\begin{array}{l}\text { EPHX1-CYP1B1-CYP2D6 } \\
{[25]}\end{array}$ \\
\hline & & $I L 2 R A-F O X P 3-I L 2 R A[12]$ \\
\hline & & $\begin{array}{l}\text { IRAK1-NOD1-MAPK7IP1 } \\
{[11]}\end{array}$ \\
\hline & & STAT6-STAT4-IFNG [26] \\
\hline & & TLR2-IL2RA-TGFBR2 [12] \\
\hline & & $\begin{array}{l}\text { B2AR-CCR3-CysLTR1- } \\
\text { FCER1B [27] }\end{array}$ \\
\hline & & $\begin{array}{l}\text { INSIG2-IL4-CHIA-ADIPOQ- } \\
\text { ALOX5 [28] }\end{array}$ \\
\hline & & $\begin{array}{l}\text { IL4-STUB1-ADRB2-IL4RA- } \\
\text { IL13RA2-CHIA [28] }\end{array}$ \\
\hline
\end{tabular}

\section{Gene-Gene Interactions on IgE Production and Asthma Development}

Allergic diseases, including atopic asthma, have long been attributed to IgE-mediated reactions, and elevation of serum IgE levels has been correlated to allergic diseases $[29,30]$. Allergic sensitization might occur in utero and be related to the future development of allergic diseases [31,32]. Elevation of cord blood IgE (CBIgE), although not sufficient to predict the development of allergic diseases in childhood [33, 34], was shown to be a risk predictor for the development of aeroallergen sensitization [35] and for later development of childhood asthma [36]. Significant associations with elevation of CBIgE levels were reported previously for cytotoxic T-lymphocyte-associated protein $4($ CTLA4) +49 A allele [37] and for IL13, CCL17, and CXCL10 gene interactions [10].

Reijmerink et al. [11] used the multifactor dimensionality reduction (MDR) analysis, which is designed to translate high-dimensional genetic data into a single dimension, to explore the gene-gene interactions on IgE production and the development of asthma. Interactions between these genes, located in the Toll-like-receptors- (TLR-) related pathway, showed that the polymorphisms in interleukin 1 receptor-like 1 (IL1RL1) and bactericidal/permeability-increasing protein $(B P I)$ were the optimal model of interaction using 2-way MDR analysis $(P=0.02)$ to predict the elevation of total IgE levels. The polymorphisms in myeloid differentiation factor (MD)-2, beta-2 integrin (ITGB2), and BPI were identified as the optimal model of the 3 -way MDR analysis $(P=0.01)$ to predict the elevation of total IgE levels at 1 to 2 years of age.

A number of gene-gene interactions implicating a link between IgE production and the development of asthma in the perinatal stage are shown in Table 1, in which more complex interactions among different immune genes are found in asthma than in IgE production. Moreover, a kinetic change of different gene profiles associated with IgE production was found in children with increasing ages. In our studies on Chinese cohorts, IgE production in infancy and toddlerhood was associated with immune and remodeling genes, and $\operatorname{IgE}$ production in preschool age was associated with MHC class II antigen genes, such as HLA-DPA1 and HLA-DQA1 (our unpublished data). These results suggest that altered immune remodeling in infancy and toddlerhood may prime children for allergic sensitization in childhood, depending on HLA genotypes.

With the introduction of powerful novel genetic-analysis tools, the heritable component of asthma has gained increasing attention over the last decade. This attention calls for open approaches to the linkage and GWA studies rather than traditional candidate gene approaches to the genetics of asthma. The main strength of GWA studies lies in their ability to discover genuinely novel disease-candidate genes, especially those associated with moderate risks [38]. In a recent GWA study for asthma, Moffatt et al. genotyped more than 317,000 single-nucleotide polymorphisms (SNPs) in 994 patients with childhood asthma and 1243 people without asthma, and identified that polymorphisms of ORM1like 3 (ORMDL3) on chromosome 17q21.1 were strongly associated with childhood asthma [39]. The association was also independently replicated in 2320 participants from a cohort of German children and in 3301 participants from the British 1958 birth cohort [39].

ORMDL3 appears to be a gene in a very old part of the human genome, and similar genes were found in primitive organisms such as yeast. Although the transcript level of ORMDL3 is strongly correlated to susceptibility to childhood asthma, its role remains unclear. Additional GWA studies on asthma are underway, and cross-validation data among these studies may lead to better conclusions on the responsible genes for the development of asthma. 


\section{Gene-Environment Interactions on IgE Production and Asthma Development}

Increasingly, more studies in the literature identify novel genes associated with asthma and suggest that numerous genes with small effects rather than few genes with strong effects contribute to the development of asthma. These genetic effects may in part differ with respect to a patient's environmental exposures. Several environmental factors, such as maternal atopy, endotoxin, tobacco smoke, pollutants, allergens, cold air, microbial infections, medication, and exercise, are known to exacerbate asthma symptoms [40-44]. Of these environmental factors, maternal atopy, microbial exposure, and tobacco smoke exposure are particularly important and its gene-environment interactions are described below.

3.1. Maternal Atopy. Allergy sensitization may occur in fetal life. Moreover, the immature immune system is highly susceptible to immunomodulatory environmental conditions, particularly in the prenatal and postnatal periods [45]. Maternal atopy may impact neonatal immune development and subsequently alter the allergic responses of neonates. A number of candidate gene studies investigating interactions between maternal atopy and airway hyperresponsiveness have also been performed for 3 main groups of genes: immunity genes (CD14, IL13, CCL22, and CTLA4), the stress gene (fibroblast growth factor 1 (FGF-1)), and the MHC class I antigen gene (HLA-G) gene. Specifically, maternal but not paternal atopy has a significant impact on $\mathrm{CBIgE}$ elevation, depending on the gender and CTLA4 $+49 \mathrm{~A} / \mathrm{G}$ polymorphism of newborns [46]. Maternal atopy interacting with the polymorphisms in IL13 and CCL22 genes was reported to be a good predictor of CBIgE elevation [10]. In contrast, in the absence of maternal atopy, the CTLA4 +49GG genotype in female newborns had a protective effect on CBIgE elevation [46].

3.2. Microbial Exposure. The prevalence of asthma is widely skewed in developed and developing countries, the reasons for which remain obscure. The hygiene hypothesis has emerged as a popular explanation. The hygiene hypothesis was initially developed to explain a reduced rate of allergic diseases among children with older siblings [56]. The underlying concept is that an increased exposure to microbes and their products during the perinatal stage protects against the development of allergic responses to common environmental antigens, such as dust mites, fungi, cockroaches, and pollens. Although abundant epidemiological studies support the hygiene hypothesis, significant inverse relations between exposures to these compounds and atopy and asthma have been found.

Protection from allergies is conferred by children growing up on small farms in parts of Europe [57], supporting this hypothesis. The specific exposure responsible for the protection against allergies afforded by this rural lifestyle is unknown, but most of the results have focused on germs and their endotoxin, which can be measured in
TABLE 2: Interactions of genes with maternal atopy, endotoxin and other environmental factors on IgE production and asthma phenotype.

\begin{tabular}{lll}
\hline & & $\begin{array}{l}\text { Environment factors-gene } \\
\text { interaction }\end{array}$ \\
\hline \multirow{3}{*}{ Prenatal } & Maternal atopy-FGF1 [10] & Maternal atopy-IL13-CCL22 [10] \\
& IgE levels & Maternal atopy-gender- \\
& CTLA4 [46] \\
& Endotoxin-CD14 [47] \\
\hline \multirow{4}{*}{ Childhood } & Animal contact-CD14 [48] \\
& & Helicobacter pylori-CD14 [49] \\
& & Endotoxin-CD14 [50] \\
& & Day care attendance-CD14 [51] \\
& & Day care attendance-IL4R [51] \\
& & Country living-CD14 [52] \\
& & Fungi-CHIT1 [53] \\
& & Maternal bronchial \\
& & hyperresponsiveness-HLA-G [54] \\
& Children of farmer-TLR2 [55]
\end{tabular}

house dust. Endotoxin, a component of the cell walls of Gram-negative bacteria, is one of the pathogen-associated molecular patterns (PAMPs). PAMPs, evolutionarily highly conserved structural components of microbes, are recognized by conserved receptors of innate immune systems, pattern-recognition receptors (PRRs), the human CD14, TLRs, nucleotide-binding oligomerization domain (NOD)1, NOD2, and C-type lectin receptors. Because the specific agent responsible for the protective effect against asthma in children with a rural upbringing is unknown, the exposure metric in some studies on gene-environment interaction on IgE levels, allergies, or asthma in children growing up on farms relies on self-reported contact with germs and other animals, as listed in Table 2.

The relationship between endotoxin exposure and IgE levels seems to be affected by a common SNP in the promoter region of $C D 14$, a receptor involved in endotoxin recognition [50]. A significant gene-environment interaction exists between the CD14-260C/T genotype and endotoxin exposure on $\mathrm{CD} 4^{+}$lymphocyte numbers, particularly $\mathrm{CD} 4^{+}{ }^{-}$oxp $3^{-}$lymphocytes at 1 year of age [47]. Interactions of IL13 with IL4R, IL13R, or CCL17, as well as the interactions of CD14 with daycare attendance, endotoxin, or rural living affect IgE production and the development of asthma in childhood [14-17, 21, 22, 50-52].

3.3. Tobacco Smoke Exposure. Previous studies have provided evidence on the role of tobacco smoke exposure (TSE) as a determinant risk factor of childhood asthma $[40,75,76]$. Recent studies suggest that in utero TSE from maternal smoking during pregnancy is associated with reduced lung function and constitutes a significant risk factor for the development of asthma [75, 77-81]. This parent-of-origin 
TABLE 3: Interactions of genes with perinatal environmental TSE and pollution on asthma development.

\begin{tabular}{ll}
\hline Stage & Environment factors-gene interaction \\
\hline & TSE-Chromosome 1q43-q44, 4q34 and 17p11 [58] \\
& TSE-ADAM33 [59] \\
& TSE-B2AR [60] \\
& TSE-GSTM1 [5, 61] \\
Prenatal & TSE-GSTP1 [62] \\
& TSE-IL1RN [63] \\
& TSE-IL13 [64] \\
& Pollution-ACSL3 [65] \\
& TSE and pollution-TGFB1 [66] \\
& TSE-Chromosome 3p and 5q [67] \\
& TSE-Chromosome 1p, 1q, 5q, 9q and 17p [68] \\
& TSE-Chromosome 1q43-q44, 4q34 and 17p11 [58] \\
& TSE-B2AR [69] \\
& TSE-CD14 [70] \\
& TSE-GSTP1 [71] \\
& TSE-GSTM1 [71] \\
& TSE-TNF [72] \\
& Pollution-GSTM1-TNF [73] \\
& Pollution-GSTP1-TNF [73] \\
& Pollution-Catalase genes-Myeloperoxidase genes [74] \\
\hline
\end{tabular}

effect points to a significant role of the maternal prenatal environment on later asthma risk in the offspring [82]. Early postnatal TSE from parents was also associated with infant wheezing and lower respiratory tract infections and increased the prevalence of asthma independently from the effect of in utero TSE from maternal smoking during pregnancy [83]. Moreover, the effect of current TSE is known not only to influence the severity of asthma, but also to impair the efficacy of inhaled corticosteroid treatments [84]. Although exposure to active and passive cigarette smoking is a well-recognized risk factor for the development of asthma, asthma manifests in only a portion of people $[85,86]$. Furthermore, Jaakkola et al. showed that a combination of parental atopy and TSE has a synergistic effect on the risk of childhood asthma [85]. This suggests that the effect of environmental factors on the development of asthma can be modified by genetic constitution.

A number of candidate gene studies investigating interactions with TSE have been performed for 3 main groups of genes: innate-immunity genes (CD14, tumor necrotic factor $(T N F)$, and IL-1 receptor antagonist (ILIRN)), adaptiveimmunity genes (IL13 and transforming growth factor (TGF)$\beta 1$ ), and response and remodeling genes (a disintegrin and metalloprotease domain-containing protein (ADAM)33, glutathione S-transferase (GST)-M1, GSTP1, and $\beta 2$ adrenergic receptor $(B 2 A R)$ ), as shown in Table 3 . Timing of exposure to TSE is also an important consideration in the analysis of gene-environment interactions on the development of childhood asthma. In the prenatal stage, the IL1RN gene polymorphism rs2234678 GG genotype significantly increased the relative risk of asthma only in children of mothers who smoked during pregnancy [63]. Reijmerink et al. showed that ADAM33 polymorphisms increased the risk of developing asthma in utero, but postnatal TSE did not [59]. A GWA study demonstrated that the chromosomes $3 p$ and $5 q$ were linked to childhood asthma in tobacco-exposed families [67]. Wang et al. [69] showed that the joint effect of the $B 2 A R$ polymorphism at position 16 with TSE increased the risk of asthma in a dose-dependent manner. Some genes were only associated with asthma in the presence of TSE $[63,64]$. In GSTM1-null children of school age, in utero exposure to smoking is associated with an increased prevalence of earlyonset asthma, asthma with current symptoms, persistent asthma, lifetime history of wheezing, wheezing with exercise, wheezing requiring medication, and number of emergency department visits in the past year in comparison to children with the GSTM1 ${ }^{+}$genotype $[61,87,88]$.

A recent study showed a synergistic effect of air pollution levels and functional SNPs within catalase and myeloperoxidase on the respiratory-related school absence of asthmatic children [74]. The exposure-traffic air pollutants also increased the effect of TGFB1 $-509 \mathrm{C} / \mathrm{T}$ polymorphism on the development of asthma [66].

\section{Environmental Influence of Epigenetic Programming for IgE Production and Asthma Development in the Postnatal Stage}

Epigenetic programming is broadly defined as heritable changes in gene expression or cellular phenotype other than changes in DNA sequences $[95,96]$. Epigenetic alterations are believed to occur not only prenatally or shortly after birth, but also during later developmental periods, influencing gene expression differentially throughout the lifespan. Although GWA studies hold promise for identifying unexpected gene-environment interactions, how the geneenvironment interactions affect IgE production and asthma development remains unclear. One of the potential mechanisms is the epigenetic programming of asthma by geneenvironment interactions in the perinatal stage. Early-life dietary supplementation and environmental exposures are known to affect adult metabolism and phenotype through alterations in DNA CG methylation [97].

Several environmental exposures reportedly interact with genetic predisposition through epigenetic mechanisms on total IgE levels and asthma phenotype (Table 4). Hollingsworth et al. are the first to report an increased risk of allergic disease in in utero dietary methyl donors because of the differential methylation of 82 genes [90]. One of these is runt-related transcription factor 3 (Runx3), a gene known to downregulate allergic airway inflammation; it is associated with decreased transcriptional activity and mRNA expression in lung tissue. DNA methylation levels of Runx3 increased in animals exposed to methyl donors in utero [90]. This effect could be transmitted to subsequent progeny mice. Runx3 is known to cooperate with T-bet in the silencing of IL-4 in Th1 cells [98]. A reduced Runx3 level might lead to enhanced transcription of IL-4 skewing toward Th2 


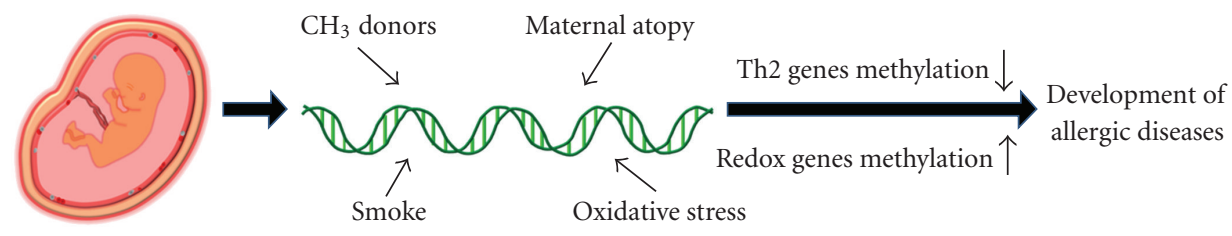

(a) Prenatal stage

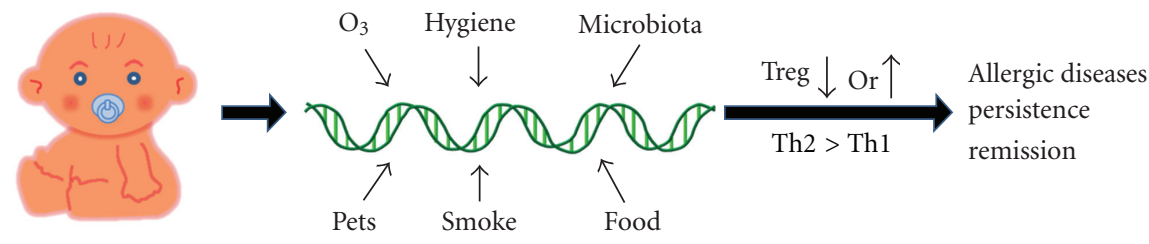

(b) Postnatal stage

FIGURE 1: Mechanisms of pre- and postnatal environmental factors on the development of asthma. A number of prenatal factors such as maternal diet with methyl donors, maternal atopy, TSE, and oxidative stress could alter the epigenetic programming of Th2 and redox genes, resulting in the allergic sensitization and diseases (a). Additional postnatal environmental conditions such as pollution, secondhand TSE, pets exposure, infant diets and microbiota may modulate or drive the expression of Treg and/or Th1/Th2 genes resulting in skewed or balanced Th2 responses that contribute to persistence or remission of allergic diseases (b).

TABLE 4: Environmental modification of epigenetic program on IgE production and asthma.

\begin{tabular}{ll}
\hline Phenotypes & Environment factors-epigenetic modification \\
\hline \multirow{3}{*}{ IgE levels } & High-fat (HF) intake-obesity [89] murine \\
& $\begin{array}{l}\text { Maternal diet with methyl donors-82 loci [90] } \\
\text { murine } \\
\\
\text { Aspergillus fumigatus-diesel exhaust particles } \\
\\
\text { (DEP)-IL4 promoter [91] murine } \\
\text { Aspergillus fumigatus-diesel exhaust particles } \\
\text { (DEP)-IFNG promoter [91] murine }\end{array}$ \\
& Folic acid supplements in pregnancy [92] \\
& A lwoffii F78-IFNG promoter [93] murine \\
& Maternal diet with methyl donors-82 loci [90] \\
& murine \\
Asthma & Pollution-ACSL3 [65] \\
& Microbial exposure-IFNG [94]
\end{tabular}

differentiation, as observed in anti-CD3 ${ }^{+} \mathrm{CD} 28^{+}$antibodystimulated $\mathrm{CD}^{+}$lymphocytes. Although the significance of epigenetic inheritance in humans is unclear, one recent study reported that folate supplements in pregnancy are associated with increased childhood wheezing [92]. In contrast, 2 cohort studies showed that dietary pattern during pregnancy was not associated with recurrent wheezing [99] or asthma and related outcomes [100].

Maternal smoking in pregnancy may feasibly impact the development of allergic airway disease through epigenetic pathways because of changes in DNA methylation or histone modifications. Air pollution has been also linked to epigenetic changes in ACSL3 [65]. Similarly, diesel exhaust particles were shown to affect CG methylation of IL4 and
IFNG promoters, which are involved in airway inflammation [91].

\section{Implications of Gene-Environment Interactions on Prevention of Asthma}

IgE production and asthma are not controlled by a single gene, but are involved in a complex interaction with environmental modification of genetic and epigenetic programming of asthma. Any individual study is unlikely to be able to account for all of the complex interactions with confounding factors in prenatal and postnatal stages and from other host factors such as maternal diets, obesity, and gender. Despite these limitations, the study of environmental epigenetics promises to help us understand the theoretically preventable disease, asthma. Environmental changes can epigenetically modulate $\mathrm{Th} 2$ and redox genes in the prenatal stage and change the Treg function and/or skewed Th2 immune reaction in the postnatal stage, as shown in Figure 1. Notable differences in the immune responses of allergic and nonallergic children are evident in utero, where environmental exposures such as maternal diet with methyl donors, maternal atopy, TSE, and oxidative stress could alter the epigenetic programming of Th2 and redox genes, resulting in allergic sensitization and diseases (Figure 1(a)). Additional postnatal environmental conditions such as pollution, secondhand TSE, pet exposure, infant diets, and microbiota may modulate or drive the expression of Treg and/or Th1/Th2 genes, resulting in skewed or balanced Th2 responses that contribute to persistence or remission of allergic diseases (Figure 1(b)). Based on the mechanisms responsible for the perinatal epigenetic and immune regulation of the development and remission of allergic diseases, we may be able to formulate potential strategies 
to prevent the development of asthma in the perinatal stage by manipulating perinatal conditions such as diet control or complementary food and by early screening of DNA methylation changes followed by modulation of CG methylation levels.

\section{Conclusion}

Increasingly, more evidence suggests that different geneenvironment interactions play an important role on $\operatorname{IgE}$ production before and after birth. We conducted a systematic review of recent studies to identify the roles of gene-gene and gene-environmental interactions on the prenatal and childhood IgE production, as well as the development of asthma. Prevention of IgE production and IgE-mediated diseases may be possible by controlling different environmental factors for patients with susceptible genotypes early in the perinatal stage. Control of maternal atopy in pregnancy and modulation of gene expression such as CTLA4 and IL13 may be a target for decreasing antenatal IgE production and possibly lowering perinatal allergy sensitization. TSE is a well-recognized risk for the development of childhood asthma; reducing the perinatal exposure of tobacco smoke may prevent the development of asthma, particularly in subjects carrying susceptible Th2 and redox genotypes. Further studies are necessary to compare genegene and gene-environment interactions on $\operatorname{IgE}$ production and asthma development in different ethnic populations and to study whether manipulations of maternal diets or postnatal complementary food could modulate epigenetic programming of asthma.

\section{Author's Contributions}

Jen-Chieh Chang and Lin Wang contributed equally to this study.

\section{Acknowledgments}

This study was in part supported by funding from Grants NSC98-3112-B-182-004 and 99-3112-B-182-004 from the National Science Council and Grants CMRPG880643 and CZRPG880253 from Chang Gung Memorial Hospital, Taiwan.

\section{References}

[1] A. J. Frew, "The immunology of respiratory allergies," Toxicology Letters, vol. 86, no. 2-3, pp. 65-72, 1996.

[2] H. Milgrom, R. B. Fick Jr., J. Q. Su et al., "Treatment of allergic asthma with monoclonal anti-IgE antibody," The New England Journal of Medicine, vol. 341, no. 26, pp. 19661973, 1999.

[3] G. Malerba and P. F. Pignatti, "A review of asthma genetics: gene expression studies and recent candidates," Journal of Applied Genetics, vol. 46, no. 1, pp. 93-104, 2005.

[4] D. Vercelli, "Advances in asthma and allergy genetics in 2007," Journal of Allergy and Clinical Immunology, vol. 122, no. 2, pp. 267-271, 2008.
[5] A. J. Rogers, C. Brasch-Andersen, I. Ionita-Laza et al., "The interaction of glutathione S-transferase M1-null variants with tobacco smoke exposure and the development of childhood asthma," Clinical and Experimental Allergy, vol. 39, no. 11, pp. 1721-1729, 2009.

[6] M. R. Warrier and G. K. Hershey, "Asthma genetics: personalizing medicine," Journal of Asthma, vol. 45, no. 4, pp. 257264, 2008.

[7] B. Schaub, J. Liu, S. Höppler et al., "Impairment of Tregulatory cells in cord blood of atopic mothers," Journal of Allergy and Clinical Immunology, vol. 121, no. 6, pp. 1491.e13-1499.e13, 2008.

[8] B. Schaub, J. Liu, S. Höppler et al., "Maternal farm exposure modulates neonatal immune mechanisms through regulatory T cells," Journal of Allergy and Clinical Immunology, vol. 123, no. 4, pp. 774.e5-782.e5, 2009.

[9] R. W. Bottema, D. S. Postma, N. E. Reijmerink et al., "Interaction of T-cell and antigen presenting cell co-stimulatory genes in childhood IgE," European Respiratory Journal, vol. 35, no. 1, pp. 54-63, 2010.

[10] K. D. Yang, J. C. Chang, H. Chuang et al., "Gene-gene and gene-environment interactions on $\operatorname{IgE}$ production in prenatal stage," Allergy, vol. 65, no. 6, pp. 731-739, 2010.

[11] N. E. Reijmerink, R. W. Bottema, M. Kerkhof et al., "TLRrelated pathway analysis: novel gene-gene interactions in the development of asthma and atopy," Allergy, vol. 65, no. 2, pp. 199-207, 2010.

[12] R. W. Bottema, M. Kerkhof, N. E. Reijmerink et al., "Genegene interaction in regulatory T-cell function in atopy and asthma development in childhood," Journal of Allergy and Clinical Immunology, vol. 126, no. 2, pp. 338.e10-346.e10, 2010.

[13] K. C. Barnes, A. Grant, P. Gao et al., "Polymorphisms in the novel gene acyloxyacyl hydroxylase (AOAH) are associated with asthma and associated phenotypes," Journal of Allergy and Clinical Immunology, vol. 118, no. 1, pp. 70-77, 2006.

[14] I. H. Chan, N. L. Tang, T. F. Leung et al., "Study of genegene interactions for endophenotypic quantitative traits in Chinese asthmatic children," Allergy, vol. 63, no. 8, pp. 10311039, 2008.

[15] T. D. Howard, G. H. Koppelman, J. Xu et al., "Gene-gene interaction in asthma: Il4ra and il13 in a dutch population with asthma," American Journal of Human Genetics, vol. 70, no. 1, pp. 230-236, 2002.

[16] H. B. Kim, Y. C. Lee, S. Y. Lee et al., "Gene-gene interaction between IL-13 and IL-13R $\alpha 1$ is associated with total IgE in Korean children with atopic asthma," Journal of Human Genetics, vol. 51, no. 12, pp. 1055-1062, 2006.

[17] I. H. Chan, T. F. Leung, N. L. Tang et al., "Gene-gene interactions for asthma and plasma total IgE concentration in Chinese children," Journal of Allergy and Clinical Immunology, vol. 117, no. 1, pp. 127-133, 2006.

[18] S. Choudhry, L. G. Que, Z. Yang et al., "GSNO reductase and $\beta 2$-adrenergic receptor gene-gene interaction: bronchodilator responsiveness to albuterol," Pharmacogenetics and Genomics, vol. 20, no. 6, pp. 351-358, 2010.

[19] S. G. Lee, B. S. Kim, J. H. Kim et al., "Gene-gene interaction between interleukin- 4 and interleukin- 4 receptor $\alpha$ in Korean children with asthma," Clinical and Experimental Allergy, vol. 34, no. 8, pp. 1202-1208, 2004.

[20] H. Corvol, A. de Giacomo, C. Eng et al., "Genetic ancestry modifies pharmacogenetic gene-gene interaction for asthma," Pharmacogenetics and Genomics, vol. 19, no. 7, pp. 489-496, 2009. 
[21] R. W. Bottema, I. M. Nolte, T. D. Howard et al., "Interleukin 13 and interleukin 4 receptor- $\alpha$ polymorphisms in rhinitis and asthma," International Archives of Allergy and Immunology, vol. 153, no. 3, pp. 259-267, 2010.

[22] N. C. Battle, S. Choudhry, H. J. Tsai et al., "Ethnicityspecific gene-gene interaction between IL-13 and IL-4R $\alpha$ among African Americans with asthma," American Journal of Respiratory and Critical Care Medicine, vol. 175, no. 9, pp. 881-887, 2007.

[23] M. Via, A. De Giacomo, H. Corvol et al., "The role of LTA4H and ALOX5AP genes in the risk for asthma in Latinos," Clinical and Experimental Allergy, vol. 40, no. 4, pp. 582-589, 2010.

[24] C. Orsmark-Pietras, E. Melén, J. Vendelin et al., "Biological and genetic interaction between tenascin $\mathrm{C}$ and neuropeptide $S$ receptor 1 in allergic diseases," Human Molecular Genetics, vol. 17, no. 11, pp. 1673-1682, 2008.

[25] A. V. Polonikov, V. P. Ivanov, and M. A. Solodilova, "Genetic variation of genes for xenobiotic-metabolizing enzymes and risk of bronchial asthma: the importance of gene-gene and gene-environment interactions for disease susceptibility," Journal of Human Genetics, vol. 54, no. 8, pp. 440-449, 2009.

[26] Y. Li, B. Wu, H. Xiong, C. Zhu, and L. Zhang, "Polymorphisms of STAT-6, STAT-4 and IFN- $\gamma$ genes and the risk of asthma in Chinese population," Respiratory Medicine, vol. 101, no. 9, pp. 1977-1981, 2007.

[27] S. H. Kim, H. H. Jeong, B. Y. Cho et al., "Association of four-locus gene interaction with aspirin-intolerant asthma in Korean asthmatics," Journal of Clinical Immunology, vol. 28, no. 4, pp. 336-342, 2008.

[28] T. M. Baye, M. B. Kovacic, J. M. Myers et al., "Differences in candidate gene association between European ancestry and African American asthmatic children," PLoS ONE, vol. 6, no. 2, Article ID e16522, 2011.

[29] B. Burrows, F. D. Marinez, M. Halonen, R. A. Barbee, and M. G. Cline, "Association of asthma with serum IgE levels and skin-test reactivity to allergens," The New England Journal of Medicine, vol. 320, no. 5, pp. 271-277, 1989.

[30] S. T. Holgate, R. Djukanović, T. Casale, and J. Bousquet, "Anti-immunoglobulin E treatment with omalizumab in allergic diseases: an update on anti-inflammatory activity and clinical efficacy," Clinical and Experimental Allergy, vol. 35, no. 4, pp. 408-416, 2005.

[31] G. Devereux, R. N. Barker, and A. Seaton, "Antenatal determinants of neonatal immune responses to allergens," Clinical and Experimental Allergy, vol. 32, no. 1, pp. 43-50, 2002.

[32] U. Herz, R. Joachim, B. Ahrens, A. Scheffold, A. Radbruch, and H. Renz, "Allergic sensitization and allergen exposure during pregnancy favor the development of atopy in the neonate," International Archives of Allergy and Immunology, vol. 124, no. 1-3, pp. 193-196, 2001.

[33] R. L. Bergmann, G. Edenharter, K. E. Bergmann et al., "Predictability of early atopy by cord blood-IgE and parental history," Clinical and Experimental Allergy, vol. 27, no. 7, pp. 752-760, 1997.

[34] G. Edenharter, R. L. Bergmann, K. E. Bergmann et al., "Cord blood-IgE as risk factor and predictor for atopic diseases," Clinical and Experimental Allergy, vol. 28, no. 6, pp. 671-678, 1998.

[35] S. M. Tariq, S. H. Arshad, S. M. Matthews, and E. A. Hakim, "Elevated cord serum IgE increases the risk of aeroallergen sensitization without increasing respiratory allergic symptoms in early childhood," Clinical and Experimental Allergy, vol. 29, no. 8, pp. 1042-1048, 1999.

[36] A. Sadeghnejad, W. Karmaus, S. Davis, R. J. Kurukulaaratchy, S. Matthews, and S. H. Arshad, "Raised cord serum immunoglobulin $\mathrm{E}$ increases the risk of allergic sensitisation at ages 4 and 10 and asthma at age 10," Thorax, vol. 59, no. 11, pp. 936-942, 2004.

[37] J. C. Chang, C. A. Liu, H. Chuang et al., "Gender-limited association of cytotoxic T-lymphocyte antigen-4 (CTLA-4) polymorphism with cord blood IgE levels," Pediatric Allergy and Immunology, vol. 15, no. 6, pp. 506-512, 2004.

[38] D. Vercelli, "Discovering susceptibility genes for asthma and allergy," Nature Reviews Immunology, vol. 8, no. 3, pp. 169$182,2008$.

[39] M. F. Moffatt, M. Kabesch, L. Liang et al., "Genetic variants regulating ORMDL3 expression contribute to the risk of childhood asthma," Nature, vol. 448, no. 7152, pp. 470-473, 2007.

[40] J. Cunningham, G. T. O'Connor, D. W. Dockery, and F. E. Speizer, "Environmental tobacco smoke, wheezing, and asthma in children in 24 communities," American Journal of Respiratory and Critical Care Medicine, vol. 153, no. 1, pp. 218-224, 1996.

[41] S. Lau, S. Illi, C. Sommerfeld et al., "Early exposure to housedust mite and cat allergens and development of childhood asthma: a cohort study," The Lancet, vol. 356, no. 9239, pp. 1392-1397, 2000.

[42] D. P. Strachan and D. G. Cook, "Parental smoking and childhood asthma: longitudinal and case-control studies," Thorax, vol. 53, no. 3, pp. 204-212, 1998.

[43] S. F. Thomsen, S. van der Sluis, L. G. Stensballe et al., "Exploring the association between severe respiratory syncytial virus infection and asthma: a registry-based twin study," American Journal of Respiratory and Critical Care Medicine, vol. 179, no. 12, pp. 1091-1097, 2009.

[44] U. Wahn, S. Lau, R. Bergmann et al., "Indoor allergen exposure is a risk factor for sensitization during the first three years of life," Journal of Allergy and Clinical Immunology, vol. 99, no. 6, part 1, pp. 763-769, 1997.

[45] N. Blümer and H. Renz, "Consumption of $\omega 3$-fatty acids during perinatal life: role in immuno-modulation and allergy prevention," Journal of Perinatal Medicine, vol. 35, supplement 1, pp. S12-S18, 2007.

[46] K. D. Yang, C. Y. Ou, T. Y. Hsu et al., "Interaction of maternal atopy, CTLA-4 gene polymorphism and gender on antenatal immunoglobulin E production," Clinical and Experimental Allergy, vol. 37, no. 5, pp. 680-687, 2007.

[47] L. K. Williams, J. Oliver, E. L. Peterson et al., "Geneenvironment interactions between CD14 C-260T and endotoxin exposure on Foxp $3^{+}$and Foxp3 $3^{-} \mathrm{CD}^{+}$lymphocyte numbers and total serum IgE levels in early childhood," Annals of Allergy, Asthma and Immunology, vol. 100, no. 2, pp. 128-136, 2008.

[48] W. Eder, W. Klimecki, L. Yu et al., "Opposite effects of CD14/-260 on serum IgE levels in children raised in different environments," Journal of Allergy and Clinical Immunology, vol. 116, no. 3, pp. 601-607, 2005.

[49] M. Virta, T. Pessi, M. Helminen et al., "Interaction between $\mathrm{CD} 14-159 \mathrm{C}>\mathrm{T}$ polymorphism and helicobacter pylori is associated with serum total immunoglobulin E," Clinical and Experimental Allergy, vol. 38, no. 12, pp. 1929-1934, 2008.

[50] L. K. Williams, R. A. McPhee, D. R. Ownby et al., "Geneenvironment interactions with CD14 C-260T and their relationship to total serum IgE levels in adults," Journal of 
Allergy and Clinical Immunology, vol. 118, no. 4, pp. 851-857, 2006.

[51] Y. Suzuki, S. Hattori, Y. Mashimo et al., "CD14 and IL4R gene polymorphisms modify the effect of day care attendance on serum IgE levels," Journal of Allergy and Clinical Immunology, vol. 123, no. 6, pp. 1408.e1-1411.e1, 2009.

[52] L. A. Smit, V. Siroux, E. Bouzigon et al., "CD14 and toll-Like receptor gene polymorphisms, country living, and asthma in adults," American Journal of Respiratory and Critical Care Medicine, vol. 179, no. 5, pp. 363-368, 2009.

[53] A. C. Wu, J. Lasky-Su, C. A. Rogers, B. J. Klanderman, and A. A. Litonjua, "Fungal exposure modulates the effect of polymorphisms of chitinases on emergency department visits and hospitalizations," American Journal of Respiratory and Critical Care Medicine, vol. 182, no. 7, pp. 884-889, 2010.

[54] C. Ober, "HLA-G: an asthma gene on chromosome 6p," Immunology and Allergy Clinics of North America, vol. 25, no. 4, pp. 669-679, 2005.

[55] W. Eder, W. Klimecki, L. Yu et al., "Toll-like receptor 2 as a major gene for asthma in children of European farmers," Journal of Allergy and Clinical Immunology, vol. 113, no. 3, pp. 482-488, 2004.

[56] D. P. Strachan, "Hay fever, hygiene, and household size," British Medical Journal, vol. 299, no. 6710, pp. 1259-1260, 1989.

[57] E. von Mutius, "Asthma and allergies in rural areas of Europe," Proceedings of the American Thoracic Society, vol. 4, no. 3, pp. 212-216, 2007.

[58] M. H. Dizier, E. Bouzigon, M. Guilloud-Bataille et al., "Evidence for gene $\times$ smoking exposure interactions in a genome-wide linkage screen of asthma and bronchial hyper-responsiveness in EGEA families," European Journal of Human Genetics, vol. 15, no. 7, pp. 810-815, 2007.

[59] N. E. Reijmerink, M. Kerkhof, G. H. Koppelman et al., "Smoke exposure interacts with ADAM33 polymorphisms in the development of lung function and hyperresponsiveness," Allergy, vol. 64, no. 6, pp. 898-904, 2009.

[60] C. Wang, M. T. Salam, T. Islam, M. Wenten, J. Gauderman, and F. D. Gilliland, "Effects of in utero and childhood tobacco smoke exposure and $\beta 2$-adrenergic receptor genotype on childhood asthma and wheezing," Pediatrics, vol. 122, no. 1, pp. e107-e114, 2008.

[61] F. D. Gilliland, Y. F. Li, L. Dubeau et al., "Effects of glutathione S-transferase M1, maternal smoking during pregnancy, and environmental tobacco smoke on asthma and wheezing in children," American Journal of Respiratory and Critical Care Medicine, vol. 166, no. 4, pp. 457-463, 2002.

[62] Y. F. Li, W. J. Gauderman, D. V. Conti, P. C. Lin, E. Avol, and F. D. Gilliland, "Glutathione S-transferase P1, maternal smoking, and asthma in children: a haplotypebased analysis," Environmental Health Perspectives, vol. 116, no. 3, pp. 409-415, 2008.

[63] R. A. Ramadas, A. Sadeghnejad, W. Karmaus et al., "Interleukin-1R antagonist gene and pre-natal smoke exposure are associated with childhood asthma," European Respiratory Journal, vol. 29, no. 3, pp. 502-508, 2007.

[64] A. Sadeghnejad, W. Karmaus, S. H. Arshad, R. Kurukulaaratchy, M. Huebner, and S. Ewart, "IL13 gene polymorphisms modify the effect of exposure to tobacco smoke on persistent wheeze and asthma in childhood, a longitudinal study," Respiratory Research, vol. 9, p. 2, 2008.

[65] F. Perera, W. Y. Tang, J. Herbstman et al., "Relation of DNA methylation of $5^{\prime}-\mathrm{CpG}$ island of ACSL3 to transplacental exposure to airborne polycyclic aromatic hydrocarbons and childhood asthma," PLoS ONE, vol. 4, no. 2, Article ID e4488, 2009.

[66] M. T. Salam, W. J. Gauderman, R. McConnell, P. C. Lin, and F. D. Gilliland, "Transforming growth factor- $\beta 1$ C-509T polymorphism, oxidant stress, and early-onset childhood asthma," American Journal of Respiratory and Critical Care Medicine, vol. 176, no. 12, pp. 1192-1199, 2007.

[67] D. A. Meyers, D. S. Postma, O. C. Stine et al., "Genome screen for asthma and bronchial hyperresponsiveness: interactions with passive smoke exposure," Journal of Allergy and Clinical Immunology, vol. 115, no. 6, pp. 1169-1175, 2005.

[68] S. Colilla, D. Nicolae, A. Pluzhnikov et al., "Evidence for gene-environment interactions in a linkage study of asthma and smoking exposure," Journal of Allergy and Clinical Immunology, vol. 111, no. 4, pp. 840-846, 2003.

[69] Z. Wang, C. Chen, T. Niu et al., "Association of asthma with $\beta_{2}$-adrenergic receptor gene polymorphism and cigarette smoking," American Journal of Respiratory and Critical Care Medicine, vol. 163, no. 6, pp. 1404-1409, 2001.

[70] S. Choudhry, P. C. Avila, S. Nazario et al., "CD14 tobacco gene-environment interaction modifies asthma severity and immunoglobulin E levels in Latinos with asthma," American Journal of Respiratory and Critical Care Medicine, vol. 172, no. 2, pp. 173-182, 2005.

[71] C. N. Palmer, A. S. Doney, S. P. Lee et al., "Glutathione Stransferase M1 and P1 genotype, passive smoking, and peak expiratory flow in asthma," Pediatrics, vol. 118, no. 2, pp. 710-716, 2006.

[72] H. Wu, I. Romieu, J. J. Sienra-Monge et al., "Parental smoking modifies the relation between genetic variation in tumor necrosis factor- $\alpha$ (TNF) and childhood asthma," Environmental Health Perspectives, vol. 115, no. 4, pp. 616$622,2007$.

[73] Y. F. Li, W. J. Gauderman, E. Avol, L. Dubeau, and F. D. Gilliland, "Associations of tumor necrosis factor G-308A with childhood asthma and wheezing," American Journal of Respiratory and Critical Care Medicine, vol. 173, no. 9, pp. 970-976, 2006.

[74] M. Wenten, W. J. Gauderman, K. Berhane, P. C. Lin, J. Peters, and F. D. Gilliland, "Functional variants in the catalase and myeloperoxidase genes, ambient air pollution, and respiratory-related school absences: an example of epistasis in gene-environment interactions," American Journal of Epidemiology, vol. 170, no. 12, pp. 1494-1501, 2009.

[75] R. Alati, A. Al Mamun, M. O'Callaghan, J. M. Najman, and G. M. Williams, "In utero and postnatal maternal smoking and asthma in adolescence," Epidemiology, vol. 17, no. 2, pp. 138-144, 2006.

[76] L. L. Magnusson, A. B. Olesen, H. Wennborg, and J. Olsen, "Wheezing, asthma, hayfever, and atopic eczema in childhood following exposure to tobacco smoke in fetal life," Clinical and Experimental Allergy, vol. 35, no. 12, pp. 15501556, 2005.

[77] F. D. Gilliland, K. Berhane, Y. F. Li, E. B. Rappaport, and J. M. Peters, "Effects of early onset asthma and in utero exposure to maternal smoking on childhood lung function," American Journal of Respiratory and Critical Care Medicine, vol. 167, no. 6, pp. 917-924, 2003.

[78] J. P. Hanrahan, I. B. Tager, M. R. Segal et al., "The effect of maternal smoking during pregnancy on early infant lung function," American Review of Respiratory Disease, vol. 145, no. 5, pp. 1129-1135, 1992.

[79] S. M. Stick, P. R. Burton, L. Gurrin, P. D. Sly, and P. N. LeSouëf, "Effects of maternal smoking during pregnancy 
and a family history of asthma on respiratory function in newborn infants," The Lancet, vol. 348, no. 9034, pp. 1060 1064, 1996.

[80] F. D. Gilliland, K. Berhane, R. McConnell et al., "Maternal smoking during pregnancy, environmental tobacco smoke exposure and childhood lung function," Thorax, vol. 55, no. 4, pp. 271-276, 2000.

[81] F. D. Martinez, M. Cline, and B. Burrows, "Increased incidence of asthma in children of smoking mothers," Pediatrics, vol. 89, no. 1, pp. 21-26, 1992.

[82] R. L. Miller and S. M. Ho, "Environmental epigenetics and asthma: current concepts and call for studies," American Journal of Respiratory and Critical Care Medicine, vol. 177, no. 6, pp. 567-573, 2008.

[83] S. Pattenden, T. Antova, M. Neuberger et al., "Parental smoking and children's respiratory health: independent effects of prenatal and postnatal exposure," Tobacco Control, vol. 15, no. 4, pp. 294-301, 2006.

[84] H. Moshammer, G. Hoek, H. Luttmann-Gibson et al., "Parental smoking and lung function in children: an international study," American Journal of Respiratory and Critical Care Medicine, vol. 173, no. 11, pp. 1255-1263, 2006.

[85] J. J. Jaakkola, P. Nafstad, and P. Magnus, "Environmental tobacco smoke, parental atopy, and childhood asthma," Environmental Health Perspectives, vol. 109, no. 6, pp. 579582, 2001.

[86] P. Nafstad, J. Kongerud, G. Botten, J. A. Hagen, and J. J. Jaakkola, "The role of passive smoking in the development of bronchial obstruction during the first 2 years of life," Epidemiology, vol. 8, no. 3, pp. 293-297, 1997.

[87] M. Kabesch, "Gene by environment interactions and the development of asthma and allergy," Toxicology Letters, vol. 162, no. 1, pp. 43-48, 2006.

[88] M. Kabesch, C. Hoefler, D. Carr, W. Leupold, S. K. Weiland, and E. von Mutius, "Glutathione S transferase deficiency and passive smoking increase childhood asthma," Thorax, vol. 59, no. 7, pp. 569-573, 2004.

[89] Y. Odaka, M. Nakano, T. Tanaka et al., "The influence of a high-fat dietary environment in the fetal period on postnatal metabolic and immune function," Obesity, vol. 18, no. 9, pp. 1688-1694, 2010.

[90] J. W. Hollingsworth, S. Maruoka, K. Boon et al., "In utero supplementation with methyl donors enhances allergic airway disease in mice," Journal of Clinical Investigation, vol. 118, no. 10, pp. 3462-3469, 2008.

[91] J. Liu, M. Ballaney, U. Al-alem et al., "Combined inhaled diesel exhaust particles and allergen exposure alter methylation of $\mathrm{T}$ helper genes and Ige production in vivo," Toxicological Sciences, vol. 102, no. 1, pp. 76-81, 2008.

[92] S. E. Håberg, S. J. London, H. Stigum, P. Nafstad, and W. Nystad, "Folic acid supplements in pregnancy and early childhood respiratory health," Archives of Disease in Childhood, vol. 94, no. 3, pp. 180-184, 2009.

[93] S. Brand, R. Teich, T. Dicke et al., "Epigenetic regulation in murine offspring as a novel mechanism for transmaternal asthma protection induced by microbes," Journal of Allergy and Clinical Immunology, vol. 128, no. 3, pp. 618.e7-625.e7, 2011.

[94] P. J. Vuillermin, A. L. Ponsonby, R. Saffery et al., "Microbial exposure, interferon gamma gene demethylation in naïve Tcells, and the risk of allergic disease," Allergy, vol. 64, no. 3, pp. 348-353, 2009.
[95] A. P. Feinberg, "Epigenetics at the epicenter of modern medicine," Journal of the American Medical Association, vol. 299, no. 11, pp. 1345-1350, 2008.

[96] R. L. Jirtle and M. K. Skinner, "Environmental epigenomics and disease susceptibility," Nature Reviews Genetics, vol. 8, no. 4, pp. 253-262, 2007.

[97] R. A. Waterland and R. L. Jirtle, "Transposable elements: targets for early nutritional effects on epigenetic gene regulation," Molecular and Cellular Biology, vol. 23, no. 15, pp. 5293-5300, 2003.

[98] I. M. Djuretic, D. Levanon, V. Negreanu, Y. Groner, A. Rao, and K. M. Ansel, "transcription factors T-bet and Runx3 cooperate to activate Ifng and silence Il4 in T helper type 1 cells," Nature Immunology, vol. 8, no. 2, pp. 145-153, 2007.

[99] N. E. Lange, S. L. Rifas-Shiman, C. A. Camargo Jr., D. R. Gold, M. W. Gillman, and A. A. Litonjua, "Maternal dietary pattern during pregnancy is not associated with recurrent wheeze in children," Journal of Allergy and Clinical Immunology, vol. 126, no. 2, pp. 250.e4-255.e4, 2010.

[100] S. O. Shaheen, K. Northstone, R. B. Newson, P. M. Emmett, A. Sherriff, and A. J. Henderson, "Dietary patterns in pregnancy and respiratory and atopic outcomes in childhood," Thorax, vol. 64, no. 5, pp. 411-417, 2009. 


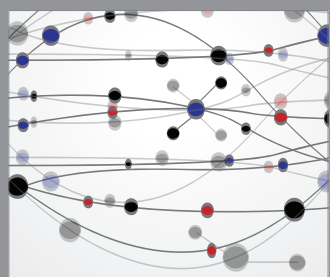

The Scientific World Journal
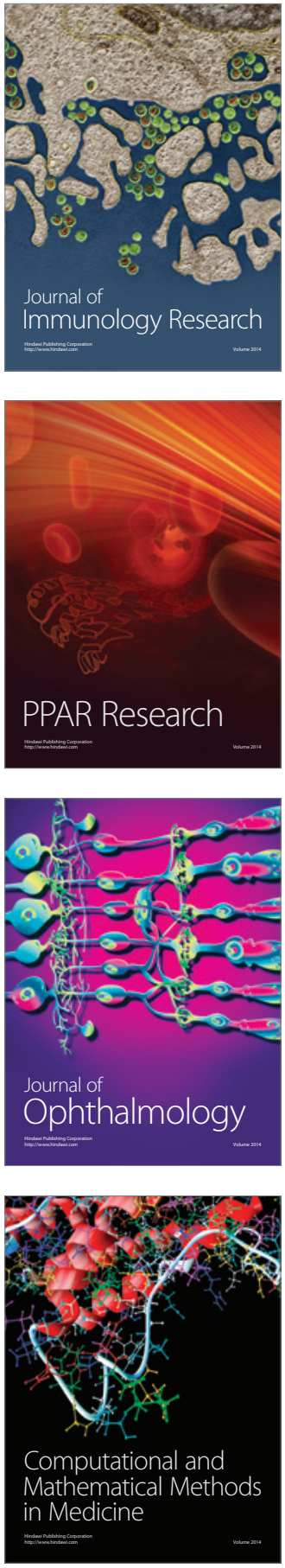

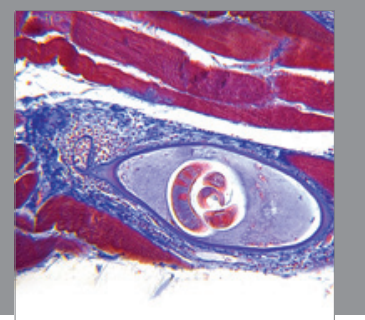

Gastroenterology

Research and Practice
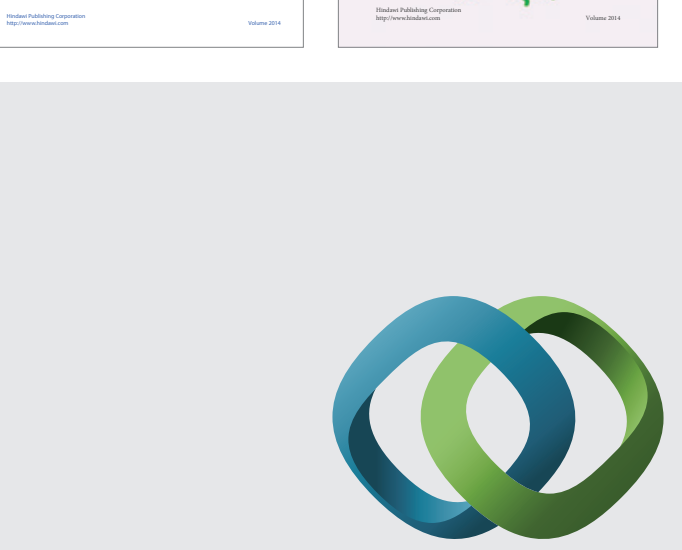

\section{Hindawi}

Submit your manuscripts at

http://www.hindawi.com
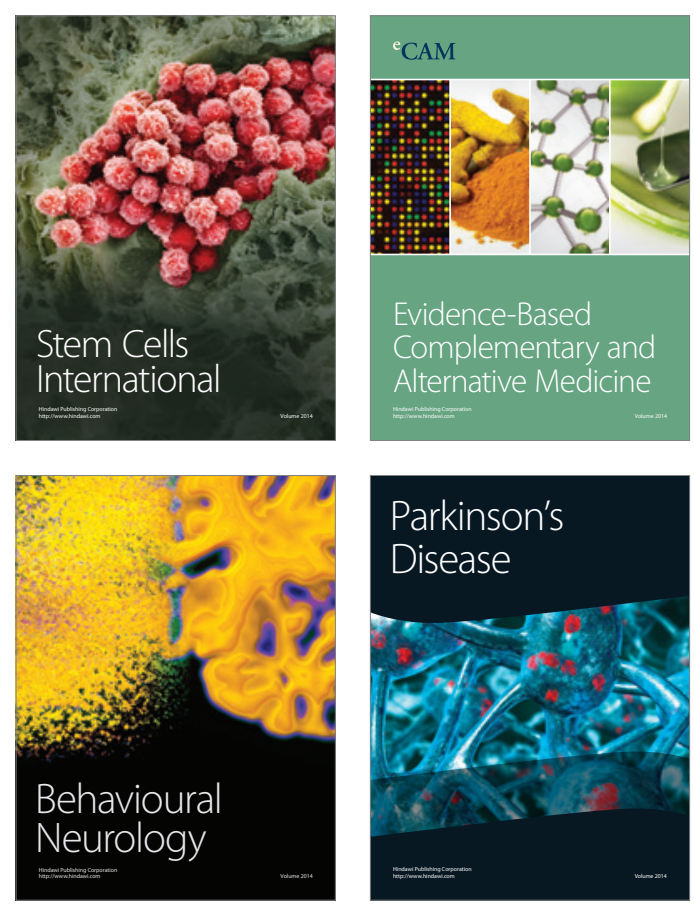

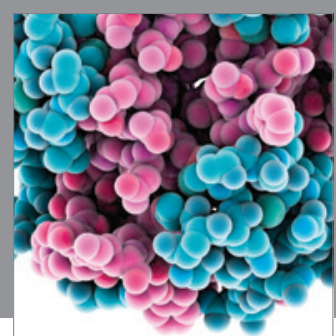

Journal of
Diabetes Research

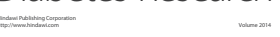

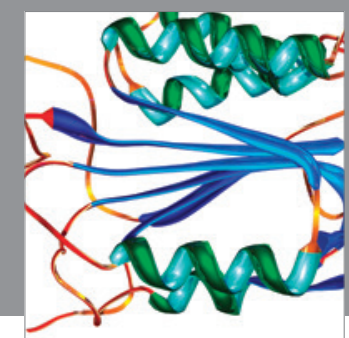

Disease Markers
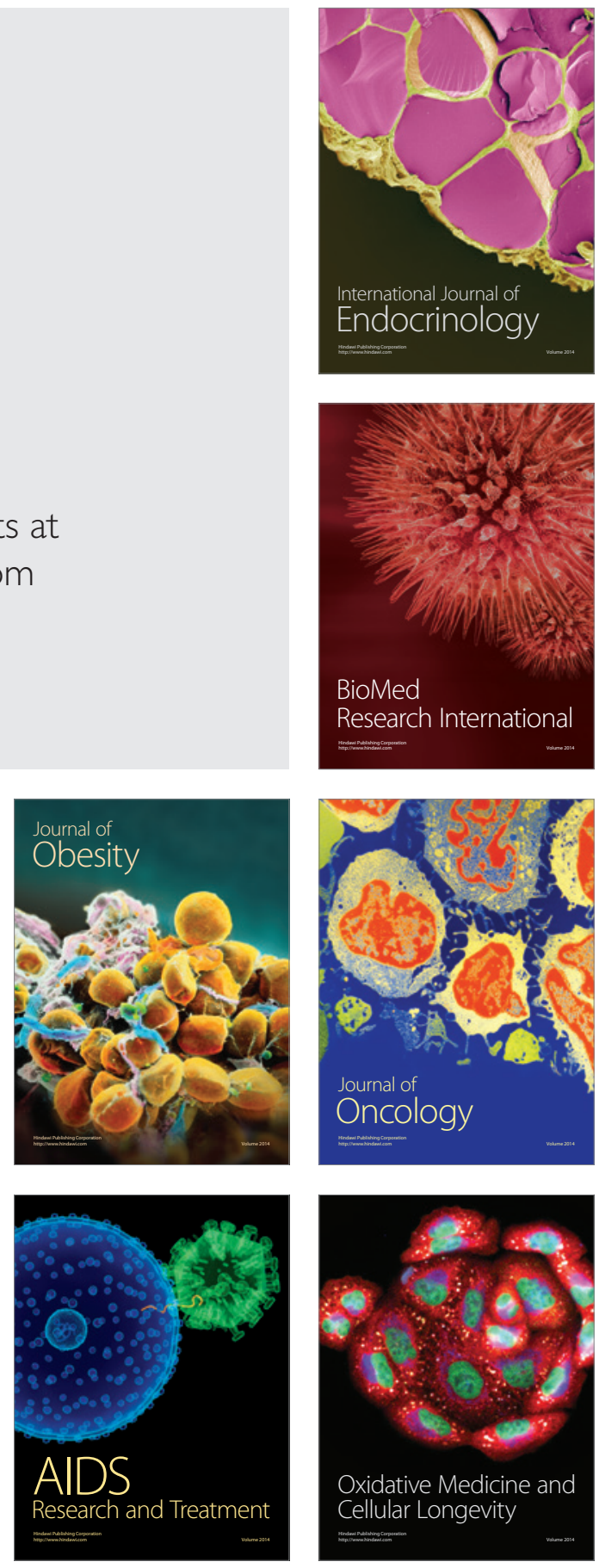